Globalization, Culture, Religion, and Values:

Comparing Consumption Patterns of Lebanese Muslims and Christians

Submitted: April 2010

Accepted: December 2010

Mark Cleveland, Ph.D. ${ }^{1}$

Aubrey Dan Program in Management and Organizational Studies, University of Western Ontario 1151 Richmond Street, Social Science Centre Room 3216,

London, Ontario, CANADA, N6A 5C2

mclevela@uwo.ca

$+1-519-661-2111$ ext. 81464

Michel Laroche, Ph.D., FRSC

John Molson School of Business, Concordia University

1455 Boulevard de Maisonneuve West, Montréal, Québec, CANADA, H3G 1M8

laroche@jmsb.concordia.ca

$+1-514-848-2424$ ext. 2942

Ranim Hallab, M.Sc. Graduate, John Molson School of Business

1455 Boulevard de Maisonneuve West, Montréal, Québec, CANADA, H3G 1M8 hallabranim@gmail.com

${ }^{1}$ Corresponding Author.

The authors gratefully acknowledge the research support provided by the Dancap Private Equity

Research Fund. The authors thank the reviewers for their comments. 


\title{
Globalization, Culture, Religion, and Values: Comparing Consumption Patterns of Lebanese Muslims and Christians
}

\begin{abstract}
Understanding the differential impact of globalization on culture - the most profound shaper of consumption - is fundamentally important. This research examines the linkages of cultural globalization (acculturation to global consumer culture, AGCC), (Lebanese) ethnic identity (LEID), religiosity (REL), individual-level (Schwartz) and consumption-related values (materialism and consumer ethnocentrism, MAT/CET) and numerous consumption behaviors; contrasting coexisting religious groups. A negative AGCC-LEID relationship exists for Muslims, whereas for Christians the two cultural forces are independent. Common across groups, religiosity and CET positively associate with LEID, and MAT positively associates with AGCC. Other relationships are religious-specific. The AGCC-LEID relationship across different behaviors yields four distinctive acculturation patterns.
\end{abstract}

Keywords: Globalization, Culture, Religion, Values, Consumption 


\section{Globalization, Culture, Religion, and Values: Comparing Consumption Patterns of Lebanese Muslims and Christians}

\section{Introduction}

Of the factors influencing consumer behavior, the most pervasive and thorny is culture. Individuals draw on consumer goods to express cultural groupings and principles, and to craft and carry on ideas and lifestyles (McCracken, 1986). Successful marketing strategies involve synchronizing product attributes and promotional appeals with those consumer attitudes fashioned by individual and cultural values. With globalization, the number of ethnically- or culturally- homogeneous nation-states dwindles. The pervasive exchanges of peoples and products across borders, coupled with the ever-accelerating interchange of technology and information bring about greater within-country cultural heterogeneity, even as similarities across countries also escalate (Merz, He and Alden, 2008). The world increasingly resembles a single market with similar needs populated by myriad cultures with different wants (i.e., ways of expressing/satisfying needs). International market segmentation requires careful consideration of similarities and differences. The research motivation is to provide insights for managers, in deciding when, where, and how marketing strategies should be standardized, adapted, or crafted anew—not just across but also within countries.

Applied to Muslim and Christian Lebanese consumers, this study investigates the differential sway of global and local cultural forces on religious subcultures' consumption patterns, across a spectrum of consumer behaviors. Ethnic identity (EID) and acculturation to global consumer culture (AGCC) denote local and global cultural forces, respectively. The research also examines how EID and AGCC link to ten individual-level values, materialism, consumer ethnocentrism, and religiosity. 


\section{Theoretical Background and Hypotheses}

\subsection{Ethnic Identity}

Identity profoundly shapes consumer behavior. A person's solidarity with a group implies the degree to which that group shapes the individual's thoughts and behaviors (Markus and Kitayama, 1991; Alden, He and Chen, 2010). EID is subjective and multidimensional, relating to perceptions of communal ancestry, common socio-cultural experiences, as well as a sense of belongingness, appreciation, and dedication, towards a given ethnic group (Rotheran and Phinney, 1987). EID also reflects adherence to culturally-expected values and behaviors (Rosenthal and Feldman, 1992), participation in ethnic customs, speaking the vernacular language, and consuming ethnic media. Ethnic attachment varies among group members; so too does the practice of the various EID facets (Cleveland and Chang, 2009). The literature testifies to the pervasive role of EID across many consumer behaviors. Research also documents contextspecific effects, reflecting that EID is more or less salient and consequently, strongly or weakly connected to consumer outcomes (Stayman and Despandé, 1989; Oswald, 1999).

\subsection{Acculturation to Global Consumer Culture}

The escalating interconnections between peoples and cultures worldwide, and the concomitant emergence of cultures not geographically anchored in one place (Hannerz, 1990) bring about global consumer culture (GCC). AGCC "considers how individuals acquire the knowledge, skills, and behaviors that are characteristic of a nascent and deterritorialized global consumer culture" (Cleveland and Laroche, 2007, p. 252). The proposed drivers of GCC are manifold; these include attitudes towards the broader collective of humanity (Hannerz, 1990; Riefler and Diamontopoulos, 2009), the culture-shaping power of the global media and marketing systems (Alden, Steenkamp and Batra, 1999), and other transnational exchanges of 
peoples, ideas, and ways of expression (Appadurai, 1990; Ger and Belk, 1996). Cleveland and Laroche's (2007) AGCC scale encompasses personal dispositions towards globalization and foreign cultures (cosmopolitanism, openness towards the lifestyles and consumption symbols of other countries, as well as an outright identity with GCC), the influences of media and marketing (specifically, global/foreign mass media exposure, and exposure to multinational marketing activities), foreign travelling attitudes/experiences, as well as English-language fluency and use.

\subsection{Behavioral Outcomes}

Berry (1980) articulates four acculturation patterns at the intersection of original and alternate cultures: assimilation (whereby alternative traits replace original ones), separation/segregation (invoked when the original is maintained while the alternate is spurned or

resisted), integration (whereby aspects of the alternative supplement rather than supplant those of the original), and marginalization (evoked when neither original nor alternate facets are maintained or adopted). Mendoza and Martinez's (1981) acculturation typology describes two distinct forms of integration: cultural incorporation (customs exhibited from both original/alternative) and cultural transmutation (fusing native/alternate traits, creating a unique entity; i.e., creolization). This typology also includes culture shift (i.e., assimilation), cultural resistance (i.e., separation/segregation).

In line with Cleveland and Laroche (2007) and following context-specific nature of EID, these patterns should differentially manifest across product-category consumption behaviors. Generally, the older the product category the greater is the effect of local conventions on behavior. Space limitations preclude a detailed review; in general, EID should figure prominently within the culture-bound categories encompassing local foods and apparel, whereas AGCC should be more preponderant with products less cemented to local traditions, such as 
consumer electronics. The sway of local/global culture on behaviors associated with appliances, durables and luxuries is less clear-cut. These products carry symbolic attributes, and may dually serve as status symbols. The meanings underlying status symbols may be global or local in origin, or a combination thereof. The study examines the consistency of these cultureconsumption patterns across religious subcultures.

\subsection{Materialism (MAT) and Consumer Ethnocentrism (CET)}

Particularly pertinent to the effects of globalization are the constructs of MAT and CET. Global cultural flows (especially, movements of meaning conveyed by global media, marketing activities, and tourism) account for the dissemination of materialistic values worldwide (Ger and Belk, 1996). MAT is "the importance ascribed to the ownership and acquisition of material goods in achieving major life goals or desired states" (Richins, 2004, p. 210). CET is ethnocentrism manifested in the marketplace. For some, foreign brands constitute economic and cultural threats. Biases towards locally-produced products signify resistance towards globalization (Steenkamp, Batra and Alden, 2003). EID and CET should concomitantly positively vary, as should AGCC-MAT. A strong local-culture affiliation affords greater immunity to global forces projecting consumption-laden values; these individuals should therefore be less materialistic. Negative relationships should emerge between AGCC-CET and EID-MAT.

\subsection{Religion and Religiosity}

Religion is an under-researched topic in marketing. Religiosity (REL) is distinct from religion. The latter is synonymous with a particular faith or creed (such as Christianity and Islam, or more specifically, e.g., Catholicism and Sunni), whereas the former portrays the focus of religion in directing a person's life in accordance with religious role expectations (Weaver and 
Agle, 2002). Defined as "the degree to which beliefs in specific religious values and ideals are held and practiced by an individual" (Swinyard, Kau and Phua, 2001, p. 17), REL is conceptualized as a continuum of commitment.

GCC is a secular force; therefore, the AGCC-REL relationship should be negative. Material passion is a form of self-promotion, and generally constitutes a moral transgression by most major religions, including the Abrahamic faiths (Judaism, Christianity, Islam). An inverse MAT-REL relationship should emerge. Religious beliefs are concordant with traditional values and norms - suggesting a positive REL-EID link.

\subsection{Schwartz Values}

Schwartz's $(1992,1994)$ value survey considers ten motivationally distinct individuallevel values (i.e., SVS-10) derived from the guiding principles of human life. Universally recognized within and across cultures, these values are relatively invariant across situations. The inclusion of the SVS stems from two objectives: to further pinpoint distinctions between the religious groups, and to assess SVS-10 relationships to AGCC and EID. Adherence to these values is the product of both the unique individual experiences and the normative sway of culture.

These values collate into a quasi-circumplex structure, along two continua. The first symbolizes relative openness to change (taking in stimulation, self-direction, hedonism) with conservation as the counterpoint (security, tradition, conformity). Adjusting to and embracing alternate cultures requires openness to change, whereas conservation emphasizes retaining and promoting the traditional way of doing things. The second continuum denotes the emphasis of self-enhancement (achievement, power), countered by self-transcendence (universalism, benevolence). The dimensions corresponding to self-transcendence involve surmounting 
personal biases in favor of an ecumenical appreciation for cultural diversity. The expected relationships for self-enhancement are mixed. Achievement suggests a predisposition to successfully navigating different cultural frameworks; power, however, implies dominion over other people and resources. Overall, AGCC should positively associate with the values underlying openness to change and self-transcendence, as well as achievement; whereas EID should positively relate to the values embedded within conservation, as well as power.

The focus is assessing the consistency of the relationships summarized in Figure 1 across religious subcultures.

\section{---FIGURE 1 HERE---}

\section{Methodology}

\subsection{Research Context}

Lebanon's strategic location on the eastern shore of the Mediterranean — at the crossroads of Africa, Asia Minor, and Arabia — combined with a history stretching back millennia, and diverse religious composition; make the country a suitable context to study the pull of traditional and global cultures. Lebanon's population unevenly distributes into several religious groups (US department of State, 2008); the largest consist of Shi'a Muslims (28\% of the population) and Sunni Muslims (also 28\%). Prominent Christian groups consist of Maronites (22\%), Greek Orthodox (8\%), and Greek Catholic (4\%). Five percent of Lebanese are Druze. Spoken universally is the vernacular Arabic. Due to Lebanon's former status as a French mandate, many Lebanese also speak French. English is also widely taught and increasingly spoken.

\subsection{The Sample}

The survey data (1000 distributed) is from Lebanese consumers. Recruitment followed a street-intercept technique, combined with snowball sampling (through collaborating local HR 
managers). Consenting individuals completed surveys in the language of their choosing (Arabic, French, or English, with 500, 150, and 350 distributed, respectively), collected after a short time interval. Half (52\%) of the respondents live in and around Beirut, 38\% live in Tripoli (the second city of Lebanon), and 11\% reside in other cities (Sidon, Zahle, Batroun, Jbeil, Jounieh, Akkar).

Overall, 399 surveys (216 Arabic, 58 French, 125 English) are retained from 200

Muslims and 192 Christians (7 non-Muslim/Christians omit from all comparisons). The sample is $52 \%$ female, $92 \%$ native-born, and $51 \%$ employed full-time. Age ranges are as follows: $\leq 18$

years (9\%), 19-20 (34\%), 25-29 (24\%), 30-39 (21\%), and $\geq 40$ (12\%). Annual family income

(AFI: Lebanese pounds [£]; \$1US $\approx £ 1500)$ ranges as follows (in millions): $\leq £ 10.9(26 \%), £ 11$ 15.9 (6\%), $£ 16-25.9$ (19\%), £26-40.9 (16\%), £41-60.9 (10\%), $\geq £ 61(23 \%)$. The sample is more educated than the Lebanese population: $30 \%$ high-school or less, $13 \%$ technical diploma, and $29 / 28 \%$ undergraduate/graduate degrees. Only for AFI $\left(\chi_{(22)}^{2}=39.4, p=.013\right)$ does an interreligious demographic difference emerge.

\subsection{The Survey}

Adopting items validated in numerous cultural contexts, including Lebanese-Canadians (Cleveland et al., 2009), the 30 items measuring Lebanese EID (LEID) cover seven facets: selfidentification/pride, desire to maintain Lebanese culture, traditional family structure and sex roles, customs/habits, Lebanese media usage/exposure, Lebanese language use, and interpersonal relationships. Drawing from Cleveland and Laroche (2007), AGCC consists of 53 items spanning six domains: cosmopolitanism, openness to GCC, global mass media exposure (with items distinguishing global media flowing from American-/European-/Asian- based sources), exposure to multinational marketing activities, attitudes towards and frequency of international travelling, and self-ascribed identification with GCC. Klein's (2002) short version of Shimp and 
Sharma's (1987) CETSCALE and Richins' (2004) material values scale measure consumer ethnocentrism (CET) and materialism (MAT), respectively. Two scales measure religiosity (REL): the Santa-Clara strength of religious faith (Lewis, Shevlin, McGuckin and Navratil, 2001) and the religious commitment inventory (RC-10: Worthington, Wade, Hight and McCullough, 2003). Within primarily Christian contexts, studies utilizing the Santa-Clara scale report high levels of internal consistency and nomological validity (see Cleveland and Chang, 2009). Mokhlis (2006) validated the RC-10 scale among Malaysian Muslims. The survey includes seven items for each of the three languages (Arabic, French, English). All the aforementioned construct items (Appendix A) measure on 7-point Likert scales (1=strongly disagree, $7=$ strongly agree).

Following Schwartz $(1992,1994,1999)$, the 56-item SVS measures ten individual-level values on 9 -point scales $(-1=$ opposed to my values, $0=$ not important, $3=$ important, $6=$ very important, 7=of supreme importance). Sixty-six items measure behaviors for product categories, following Cleveland (2007). These include 11 Lebanese foods, 11 global foods, 4 restaurant-type patronages, 6 fashions/apparel items, 4 hygiene items, 7 appliances/durables, 8 consumer electronics, 7 technology behaviors, and 8 luxuries. The relevant literature (e.g., Cleveland et al., 2009) guided the choice of the Lebanese-food items, consisting of staples and main dishes. These dependent measures are on 7-point scales; endpoints depend on the nature of the behavior (Appendix B). The survey also contains demographic measures.

Separate offices translated the English-language questionnaire into French and Arabic. Third and fourth translation offices performed back-translations into English. Although there were no major issues of equivalency, a few trivial vocabulary changes improved consistency.

\section{Analyses and Results}




\subsection{Factor Analyses and Mean Differences}

Exploratory factor analyses (Principal components, oblimin rotation), identifies unstable items and assesses the dimensionality of LEID, AGCC, REL, MAT, CET, and language measures. Both the KMO test of sampling adequacy and Bartlett's test of sphericity underscore the appropriateness of the data for factor analysis. Factor results (eigenvalues >1) and retained items/loadings appear Appendix A. For each factor, reliabilities (Cronbach's alphas: $\alpha$ ), and descriptives are calculated for the overall sample, for each language version, and for each religious subsample. For the most part, the results are satisfactory, with most $\alpha$ 's exceeding .70 . AGCC comprises 8 factors: English language usage (ELU), cosmopolitanism (COS), Americanbased and European-based global mass media (GMMUSA, $\left.\mathrm{GMM}_{\mathrm{EURO}}\right)$, openness to GCC (OPGCC), exposure to multinational marketing activities (EXM), travelling frequencies/attitudes (TRAV), and self-identification with GCC (GCIDT). LEID comprises 4 factors: pride and desire to maintain Lebanese EID (PDMLEID), Arabic-language use (ALU), Arabic-media usage (AMU), and ethnic customs (ECUS). Reliable factors for French-language use (FLU), materialism (MAT), and consumer ethnocentrism (CET) also emerge. Two factors emerge for Religiosity. The first (REL1) denotes the intensity of faith and religion as a guiding force in dayto-day life; the second (REL2), religious activities. The mean of the constituent items serves as the construct measure. Composite AGCC and LEID scores (averaging constituent factors) are also calculated.

Following Schwartz's (2007), the SVS-10 factors were calculated controlling response differences with the SVS. Individuals' mean ratings (MRAT: across 56 items) constitutes a covariate. MANCOVA (controlling for MRAT and AFI) and multiple discriminant analysis (MDA) assesses differences between the two religious groups on the ten Schwartz value 
dimensions. MANCOVA reveals a significant overall difference $\left(\Lambda=.939, \mathrm{~F}_{10}=2.46, \mathrm{p}=.007\right)$ between Muslim (M) and Christian (C) means on the combination of SVS-10 dimensions. Significant univariate differences (Appendix A) appear on 6 facets: conformity $(M>C)$, benevolence $(\mathrm{M}>\mathrm{C})$, stimulation $(\mathrm{M}<\mathrm{C})$, hedonism $(\mathrm{M}<\mathrm{C})$, power $(\mathrm{M}<\mathrm{C})$, and security $(\mathrm{M}>\mathrm{C})$. The MDA function correctly classifies $62 \%$ (i.e., $60 / 65 \%$ of Muslims/Christians) of cases into their original sample, exceeding Hair, Anderson and Tatham's (1987) cutoff. These results uphold the distinctiveness of the groups.

MANCOVA (controlling for AFI) identifies inter-religious mean differences on the remaining constructs (Table 1, Appendix A). Significant differences are found for the overall AGCC composite score $(\mathrm{M}<\mathrm{C})$, as well as for 5 of the 8 AGCC factors - upon all of which Christians outscore their Muslim counterparts: ELU, GMMUSA, GMM $\mathrm{GURO}_{\mathrm{EO}}$, OPGCC, and TRAV. For the LEID constructs, interreligious differences are not significant; neither on the LEID composite nor along any of the constituent factors. Interreligious differences on MAT, CET and REL1 are likewise not significant. Differences on REL2 and FLU are significant, with Christians outscoring their Muslim counterparts on both.

\section{---TABLE 1 HERE---}

\subsection{Correlation Analyses}

Partial correlations (controlling AGI, and where necessary, MRAT) appear in Appendix C. For space considerations, the focus is on relationships with AGCC and LEID, identifying between-group similarities/differences. First, the inverse AGCC-LEID relationship is significant only for Muslims, implying that the acquisition of global culture is associated with a diminishment of traditional identity (alternatively, greater motivation to maintain LEID entails resistance to GCC). Among Christians, these cultural forces are independent. For religiosity, 
REL1 and REL2 both robustly positively associate with LEID. Only among Christians is AGCCREL2 significant (+). The MAT-AGCC relationship is positively significant for both groups. Only among Christians is LEID-MAT significant (+). As expected, the LEID-CET link is robustly positive, however, the predicted negative AGCC-CET relationship exists only for Muslims. Concerning Schwartz's values, as expected and common across groups, conformity and tradition negatively relate to AGCC whereas stimulation and hedonism positively relate to AGCC. Unexpectedly, AGCC positively links to power. For EID, the only individual-level relationship common across groups is that for stimulation (-).Other significant relationships are religious-group-specific; all in the expected direction. For Muslims, these are LEID-tradition (+) and LEID-hedonism (-). For Christians, these are AGCC-self-direction (+), AGCC-security (-), LEID-conformity (+), LEID-self-direction (-), and LEID-security (+).

\subsection{Regression Analyses}

Stepwise multiple linear regression analyses (MLR) examine the relationships of LEID and AGCC to consumption, with AGCC, LEID and AGCCxLEID (interaction: A*L) as predictors, and the behaviors as dependent variables. The stepwise procedure guards against multicollinearity, as predictors enter into the regression only if they uniquely explain additional dependent variable variance. Separate MLRs denote each of the 66 behaviors (Table 2). The valence/magnitude of the predictors is highly variable across products and categories. AGCC is significant for 28 behaviors, of which all but two (tea, traditional-fashions) are positivelyvalenced. $A * \mathrm{~L}$ is significant in 26 cases (only one negative: kebbe), while LEID is significantly predictive in 18 episodes ( 3 negative: European-fashions, CD-player, jewelry). In only 8 cases are LEID and AGCC jointly significant (e.g., watching-television). The magnitude of AGCC appears greatest for global foods and for communication/media behaviors, whereas LEID figures 
prominently for local foods. The interaction term is significant for at least one behavior, in all product categories. A positive interaction suggests integration/creolization.

\section{---TABLE 2 HERE--- \\ ---FIGURES 2-3 HERE---}

\subsection{Patterns of Culture in Consumption}

The next analyses contrast interreligious acculturation patterns, by running and comparing regressions (omitting the interaction) across the groups. The results appear in Figures 2-3, according to the magnitude/sign of the standardized beta coefficients for AGCC (vertical axis) and LEID (horizontal axis). The greater the distance a behavior appears from the zero intercept(s) the greater is the magnitude of the construct(s) relationship to that behavior. Behaviors on or near (i.e., coefficient roughly $<| \pm 0.14|$ ) the intercept(s) are not significantly related to the corresponding construct(s). For example, among Muslims, LEID significantly positively predicts watching-television, whereas AGCC is not significant. Following Berry (1980), dichotomizing the 2 constructs yields four distinct acculturation patterns.

\section{---TABLE 3 HERE---}

Among Muslims, assimilation (culture shift) is the most common pattern (a significant positive AGCC slope, and a negative or non-significant LEID slope), with 26 assimilation-like behaviors compared to 18 for Christians (Table 3). Fourteen items are common to both groups, most pertaining to the consumption of foreign/global foodstuffs and fashions. The remaining assimilation episodes are religious-group specific. Assimilation evidences among Muslims for the ownership of several consumer electronics and most technology behaviors.

Among Christians, integration (cultural incorporation/creolization) is the most frequent pattern, represented in 19 cases compared to only 10 for Muslims. Here, AGCC and LEID slopes 
are both positively significant. Only one item is common: Lebanese-restaurant patronage. For Muslims, integration describes a substantial proportion of luxury good consumption, whereas for Christians, this pattern describes consumption for considerable number of hygiene products and appliances, as well as consumer electronics and associated technology behaviors.

Forms of cultural resistance appear when a positive coefficient for LEID is accompanied with either a non-significant (i.e., independent from AGCC, thus separation) or a negative (i.e., active resistance towards AGCC, implying segregation) coefficient for AGCC. Eleven (9) cases of separation appear for Muslims (Christians), along with 3 (Muslims) and 2 (Christians) cases of segregation. Five items imply separation for both groups (manakish, oriental-sweets, taboulleh/fattoush, TV-set, washing-machine), whereas Lebanese-fashion denotes segregation across both groups. The remaining items under separation/segregation are religious-group specific, yet for both groups the bulk pertain to local foods.

Marginalization behaviors entail a significant negative coefficient for LEID without corresponding replacement by AGCC. No such pattern evidenced for either group. Deculturation describes behaviors independent from either cultural influence (with both coefficients nonsignificant they are absent from Figures 2-3. Sixteen (18) behaviors corresponding to deculturation emerge for Muslims (Christians). Common across the groups are eight eclectic products: pizza, croissants, arak, shawarma, hair-shampoo, athletic-shoes, bicycle, and antiquefurniture. Other deculturation behaviors are religious-group specific.

\section{Discussion and Conclusions}

Verifying the underlying causes for these subgroup differences necessitates additional research, as cross-sectional data precludes definitive cause-and-effect relationships. This study nonetheless sheds considerable light on the linkages between culture, religion, values and 
consumption, illustrating how globalization differentially affects these relationships across major coexisting subcultures. This research extends the scant empirical work on the effects of religion (and associated concepts like religiosity), underscoring the significance of religion for national and international segmentation purposes.

Consistently for Muslims and Christians, materialistic values run in lockstep to the acquisition of global consumer culture, whereas levels of consumer ethnocentrism and religiosity (both REL factors) both rise and fall with LEID. Uniformly across the religious groups are the Schwartz-value linkages of AGCC to conformity and tradition (-), stimulation and hedonism (+), and power (+); as well as LEID and stimulation (-). Despite these similarities, the results clearly show that globalization unevenly impacts subcultures within countries; represented here by different religious communities (clearly distinguished by MANCOVA and discriminant analysis). For example, an inverse AGCC-LEID relationship exists for Muslims (implying that acquiring aspects of the former leads to shedding facets of the latter), whereas the relationship was independent for Christians. For Muslims, MAT and LEID are independent from one another; for Christians, one reinforces the other. For Christians, the AGCC-CET link is not significant, whereas the association is strongly negative for Muslims. Other between-group differences are the associations between numerous SVS dimensions and AGCC/LEID.

In many instances the consumption patterns of the religious groups converge, with respect to the roles played by local/global cultural influences. The behaviors falling under assimilation (itself implying increasing across-cultural homogeneity) are the most preponderant in consistency, with 14 shared instances. However, with integration/creolization, very few behavioral similarities emerge, despite the fact that integration implies the complementary mixing of local and global cultural elements. With the other acculturation patterns, the 
differences are more recurrent than the communalities. Consumption patterns corresponding to assimilation and segregation are more frequent for Muslims (vs. Christians), whereas integration/creolization and deculturation are more prevalent for Christians (vs. Muslims). These results reflect in part the historical legacy of the French mandate (1920-1946), whereby the (also Christian) French rulers favored Lebanese Christians, over Lebanese of other faiths. Very likely more Western in orientation than their Muslim counterparts, Lebanese-Christians are consequently more able to integrate local and global traits, as these cultural forces are less in conflict, when compared to Lebanese-Muslims. This conjecture flows from the SVS findings. Christian-Lebanese outscore their Muslim counterparts on stimulation, hedonism, and powervalues congruent with AGCC as evidenced by the correlations-whereas Muslims score higher on conformity and security, which negatively associate with AGCC. As expected, global-food consumption primarily reflects assimilation, whereas local-food consumption clusters under separation/segregation. The most striking between-group differences appear for integration/creolization, which describes the consumption of luxuries for Muslims, whereas for Christians this pattern applies to consumer electronics, appliances and technology behaviors. For Muslims, modern communication products and associated behaviors cluster under assimilation. Together, these results cast doubt on the appropriateness of using the country as the primary basis for international market segmentation (Craig and Douglas, 2005). Despite close geographic proximity and living side-by-side for centuries, each group retains many distinctions, in terms of the relationships between constructs associated with globalization and culture, and the subsequent impact of these constructs on consumption behavior. These empirical results cannot generalize to different cultures; however, the findings of distinctiveness between subcultural groups are very likely to manifest in other national settings (e.g., French/English- 
speaking Canadians, Walloon/Flemish Belgians, and immigrant subcultures coexisting within

mainstream cultures).

International marketing managers recognize that strategies often need to be adapted

across countries. Globalization encourages greater homogeneity among consumers worldwide

yet the results suggest that globalization simultaneously upholds differences among people

within national boundaries.

\section{References}

Alden, DL, He Y, Chen Q. Service recommendations and customer evaluations in the international marketplace: cultural and situational contingencies. J Bus Res 2010;63(1):3844.

Alden, DL, Steenkamp J-BEM, Batra R. Brand positioning through advertising in Asia, North America, and Europe: the role of global consumer culture. J Mark 1999;63(1):75-87.

Appadurai A. Disjuncture and difference in the global economy. Theory Cult Soc 1990;7(2/3):295-310.

Berry JW. Acculturation as varieties of adaptation. In: Padilla AM, editor. Acculturation: theory, models, and some new findings. Boulder, CO: Westview; 1980. p. 9-25.

Cleveland M. Globals, locals, and creoles: acculturation to global consumer culture, ethnic identity, and consumptionscapes. Saarbrücken, Germany: VDM Verlag Dr. Müller; 2007.

Cleveland M, Chang W. Migration and materialism: the roles of ethnic identity, religiosity, and generation. J Bus Res 2009;62(10):963-71.

Cleveland M, Laroche M. Acculturation to the global consumer culture: scale development and research paradigm. J Bus Res 2007;60(3):249-59.

Cleveland M, Laroche M, Pons F, Kastoun R. Acculturation and consumption: textures of cultural adaptation. Int J Intercult Rel 2009;33(3):196-212.

Craig CS, Douglas S. Beyond national culture: implications of cultural dynamics for consumer research. Int Mark Rev 2005;23(3):322-42.

Ger G, Belk RW. Cross-cultural differences in materialism. J Econ Psychol 1996;17(1):55-77.

Hair J, Anderson R, Tatham R. Multivariate data analysis $2^{\text {nd }}$ Ed. New York: MacMillan; 1987.

Hannerz U. Cosmopolitans and locals in world culture. Theory Cult Soc 1990;7(2-3):237-51.

Klein JG.Us versus them, or us versus everyone? Delineating consumer aversion to foreign goods," J. Int Bus Stud 2002;33(2):345-63.

Lewis CA, M. Shevlin M, McGuckin C, Navratil M. The Santa Clara strength of religious faith questionnaire: confirmatory factor analysis. Pastor Psychol 2001;49(5):379-84.

Markus HR, Kitayama S. Culture and the self: implications for cognition, emotion, and motivation. Psychol Rev 1991;98(6):224-53.

McCracken G. Culture and consumption: a theoretical account of the structure and movement of the cultural meaning of consumer goods. J Consum Res 1986;13(1):71-84.

Mendoza RH, Martinez JL. The measurement of acculturation. In: Baron A. editor. Explorations in Chicano psychology. New York: Praeger; 1981. p.71-82. 
Merz MA, He Y, Alden DL.A categorization approach to analyzing the global consumer culture debate. Int Mark Rev 2008;25(2):166-182.

Mokhlis S. The effect of religiosity on shopping orientation: an exploratory study in Malaysia. J Amer Acad Bus 2006;9(1):64-74.

Oswald LR. Culture swapping: consumption and the ethnogenesis of middle-class Haitian immigrants. J Consum Res 1999;25(4):303-18.

Riefler P, Diamantopoulos A. Consumer cosmopolitanism: review and application of the CYMYC scale. J Bus Res 2009;62(4):407-19.

Richins ML. The material values scale: measurement properties and development of a short form. J. Consum Res 2004;31(1):209-19.

Rosenthal DA, Feldman SS. The nature and stability of ethnic identity in Chinese youth: effects of length of residence in two cultural contexts. J Cross-Cult Psychol 1992, 23:214-27.

Rotheran MJ, Phinney JS. Children's ethnic socialization. London: Sage; 1987.

Schwartz SH. Universals in the content and structure of values: theoretical advances and empirical tests in 20 countries. In: Zanna MP, editor. Advances in Experimental Social Psychology, vol. 25. San Diego: Academic Press; 1992. p. 1-65.

Schwartz SH. Beyond individualism/collectivism: new dimensions of values. In: Kim U, Triandis HC, Kagitcibasi C, Choi SC, Yoon G, editors. Individualism and collectivism: theory, application and methods. Newbury Park, CA: Sage; 1994. p. 85-122.

Schwartz SH. A theory of cultural values and some implications for work. App Psychol Int Rev 1999;48(1):23-47.

Schwartz SH. Draft users manual: proper use of the Schwartz value survey, version 10, September 2007, compiled by R.F. Litrell. Auckland, New Zealand: Centre for CrossCultural Comparisons, http://www.crossculturalcentre.homestead.com.

Shimp TA, Sharma S. Consumer ethnocentrism: construction and validation of the CETSCALE. J Mark Res 1987;24(8):280-89.

Stayman DM, Deshpandé R. Situational ethnicity and consumer behavior. J Consum Res 1989;16(3):361-71.

Steenkamp J-BEM, Batra R, Alden DL. How perceived globalness creates brand value. J. Int Bus Stud 2003;34(1):53-65.

Swinyard WR, Kau AK, Phua HY. Happiness, materialism, and religious experience in the US and Singapore. Journal of Happ Stud 2001;2:13-32.

US Department of State (2008). http://www.state.gov/g/drl/rls/irf/2008/108487.htm. Retrieved April 1, 2010.

Weaver GR, Agle BR. Religiosity and ethical behavior in organizations: a symbolic interactionist perspective. Acad Manag Rev 2002;27(1):77-98.

Worthington EL, Wade NG, Hight TL, McCullough ME. The religious commitment inventory10: development, refinement, and validation of a brief scale for research and counseling. J. Counsel Psychol 2003;50(1):84-96. 
Figure 1: Summary of Relationships

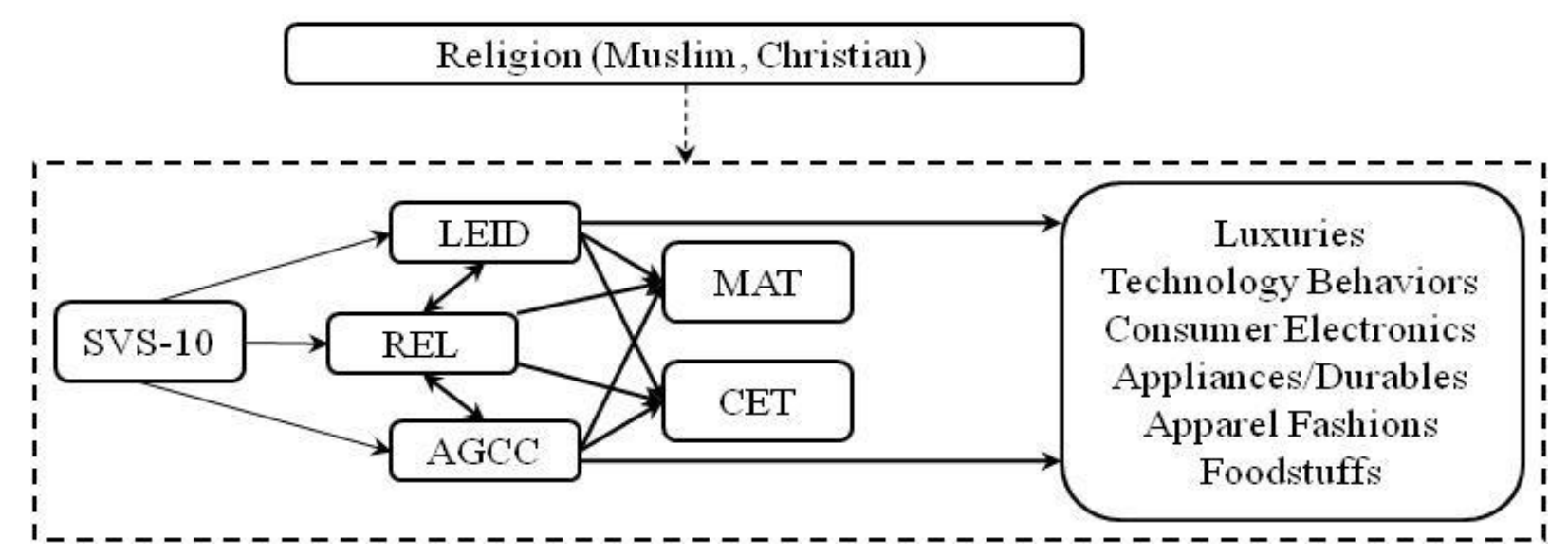


Figure 2: Lebanese-Muslim Consumption Patterns

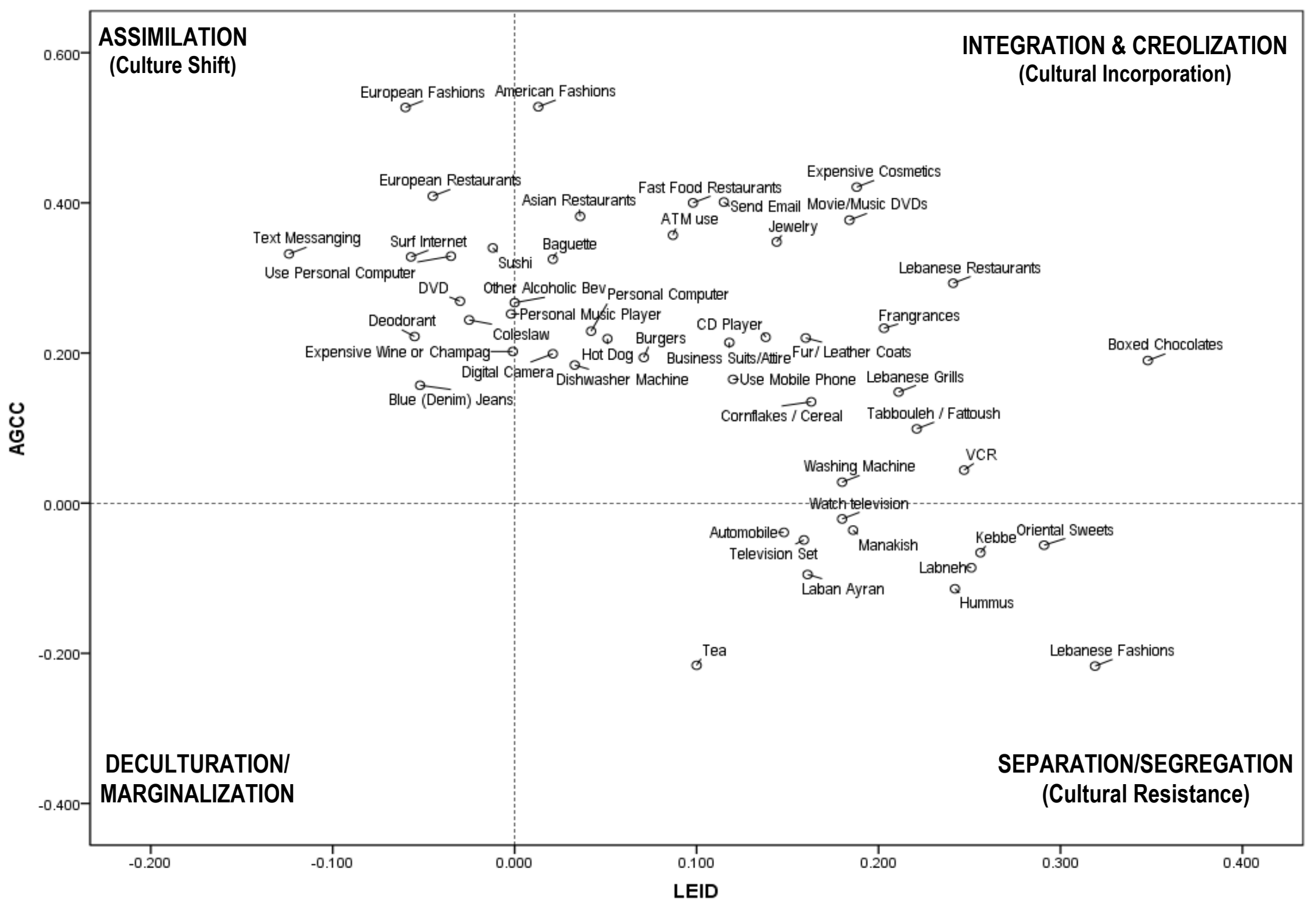


Figure 3: Lebanese-Christian Consumption Patterns

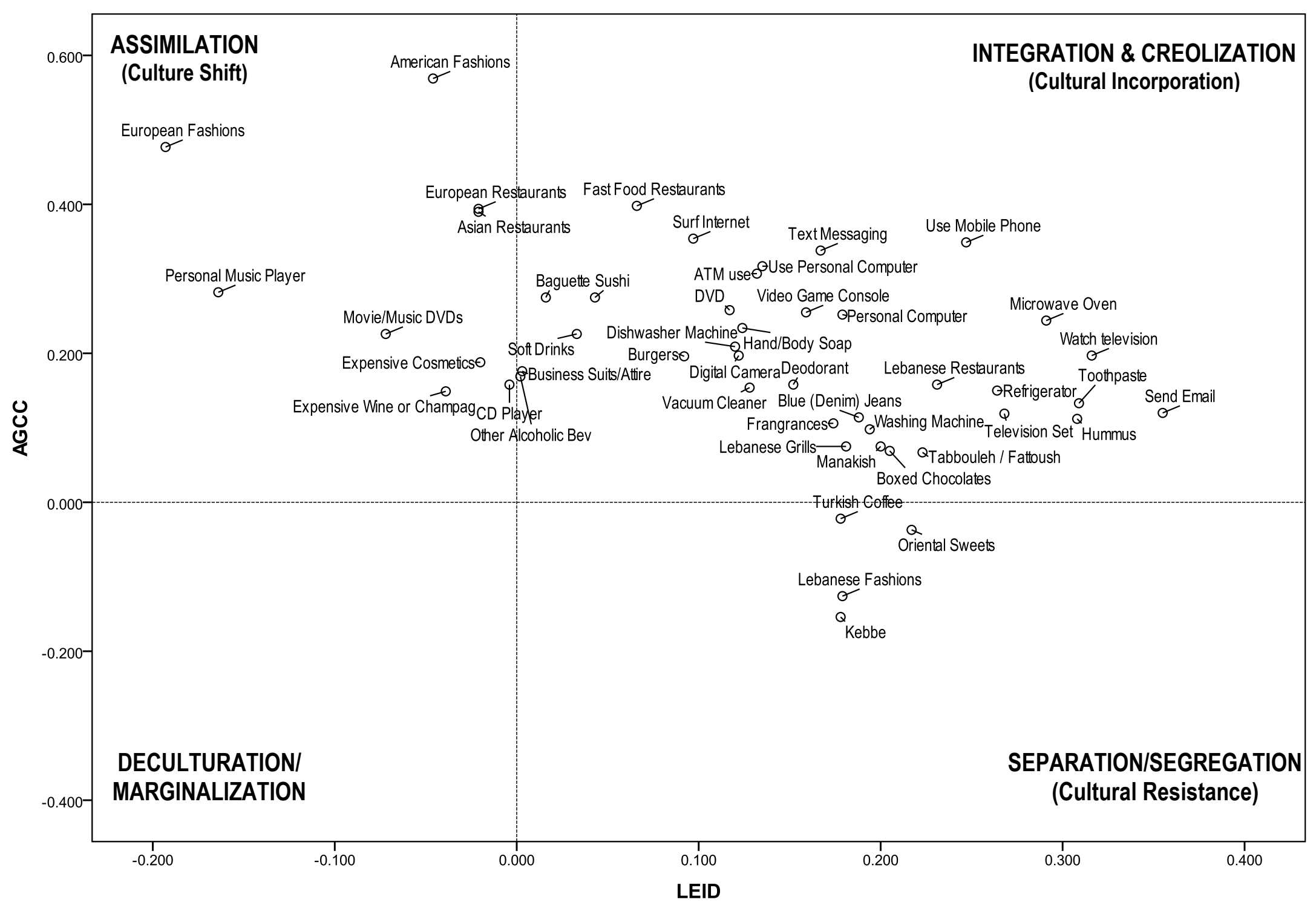


Table 1: Summary of Construct Findings

\begin{tabular}{l|c}
\hline \multicolumn{1}{c|}{ Construct } & Finding \\
\hline English-Language Use & $\mathrm{M}<\mathrm{C}$ \\
Cosmopolitanism & $\mathrm{M}=\mathrm{C}$ \\
Global Mass Media-USA & $\mathrm{M}<\mathrm{C}$ \\
Global Mass Media-Europe & $\mathrm{M}<\mathrm{C}$ \\
Openness to GCC & $\mathrm{M}<\mathrm{C}$ \\
Exposure to Marketing Activities of MNC's & $\mathrm{M}=\mathrm{C}$ \\
Travelling Frequencies/Attitudes & $\mathrm{M}<\mathrm{C}$ \\
Self Identification with GCC & $\mathrm{M}=\mathrm{C}$ \\
AGCC Composite & $\mathrm{M}<\mathrm{C}$ \\
\hline Pride and Desire to Maintain Lebanese Ethnic Identity & $\mathrm{M}=\mathrm{C}$ \\
Arabic-Language Use & $\mathrm{M}=\mathrm{C}$ \\
Arabic-Media Usage & $\mathrm{M}=\mathrm{C}$ \\
Ethnic Customs & $\mathrm{M}=\mathrm{C}$ \\
EID Composite & $\mathrm{M}=\mathrm{C}$ \\
\hline Materialism & $\mathrm{M}=\mathrm{C}$ \\
Consumer Ethnocentrism & $\mathrm{M}=\mathrm{C}$ \\
Religiosity Factor 1 & $\mathrm{M}=\mathrm{C}$ \\
Religiosity Factor 2 & $\mathrm{M}=\mathrm{C}$ \\
French-Language Usage & $\mathrm{M}<\mathrm{C}$ \\
\hline Conformity & $\mathrm{M}>\mathrm{C}$ \\
Tradition & $\mathrm{M}=\mathrm{C}$ \\
Benevolence & $\mathrm{M}>\mathrm{C}$ \\
Universalism & $\mathrm{M}=\mathrm{C}$ \\
Self-Direction & $\mathrm{M}=\mathrm{C}$ \\
Stimulation & $\mathrm{M}<\mathrm{C}$ \\
Hedonism & $\mathrm{M}<\mathrm{C}$ \\
Achievement & $\mathrm{M}=\mathrm{C}$ \\
Power & $\mathrm{M}<\mathrm{C}$ \\
Security & $\mathrm{M}>\mathrm{C}$ \\
\hline M-Mim CEChi & \\
\hline
\end{tabular}

$\mathrm{M}=$ Muslim, $\mathrm{C}=$ Christian. $</>$ significant ( $\mathrm{p}<.05$ ) differences; =non significant. 
Table 2: Culture and Behavior*

\begin{tabular}{|c|c|c|c|c|c|c|c|c|c|}
\hline & AGCC & LEID & $\mathbf{A} * \mathbf{L}$ & $\mathbf{R}^{2}$ & & AGCC & LEID & $\mathbf{A} * \mathbf{L}$ & $\mathbf{R}^{2}$ \\
\hline Global Foods/Beverages & & & & & Consumer Electronics & & & & \\
\hline 1. Pizza & & & $.156 \mathrm{a}$ & .024 & 37. Personal-Stereo-Player & $.270 \mathrm{a}$ & & & .073 \\
\hline 2. Sushi§ & $.333 \mathrm{a}$ & & & .111 & 38. Videogame-Console & & & $.240 \mathrm{a}$ & .058 \\
\hline 3. Hamburgers & $.195 \mathrm{a}$ & & & .038 & 39. VCR & & $.189 \mathrm{a}$ & & .036 \\
\hline 4. Croissants & & & $.103 \mathrm{~b}$ & .011 & 40. DVD-player§ & $.285 \mathrm{a}$ & & & .081 \\
\hline 5. Baguette & $.300 \mathrm{a}$ & & & .090 & 41. Digital-camera & $.211 \mathrm{a}$ & & & .044 \\
\hline 6. Alcoholic-beverages $\S$ & $.304 \mathrm{a}$ & & & .092 & 42. TV-set & & & $.203 \mathrm{a}$ & .041 \\
\hline 7. Cold cereals & & & $.149 \mathrm{a}$ & .022 & 43. Personal-computer & & & $.226 \mathrm{a}$ & .051 \\
\hline 8. Tea§ & $-.156 a$ & & & .024 & 44. CD-player & & $-.120 b$ & $.264 \mathrm{a}$ & .051 \\
\hline 9. Soft-drinks & & & $.134 \mathrm{a}$ & .018 & Appliances/Durables & & & & \\
\hline 10. Coleslaw & $.166 \mathrm{a}$ & & & .027 & 45. Washing-machine & & $.183 a$ & & .034 \\
\hline 11. Hotdog $\S$ & $.201 \mathrm{a}$ & & & .040 & 46. Refrigerator & & $.145 \mathrm{a}$ & & .021 \\
\hline 12. Asian-restaurants $\S$ & $.409 \mathrm{a}$ & & & .167 & 47. Microwave§ & & & $.200 \mathrm{a}$ & .040 \\
\hline 13. European-restaurants $\S$ & $.414 a$ & & & .172 & 48. Dishwasher§ & $.230 \mathrm{a}$ & & & .053 \\
\hline 14. American fast-food-restaurants & $.391 \mathrm{a}$ & & & .153 & 49. Vacuum§ & & & $.148 \mathrm{a}$ & .022 \\
\hline $\begin{array}{l}\text { Lebanese Foods/Beverages } \\
\end{array}$ & & & & & 50. Bicycle & & & $.123 \mathrm{a}$ & .015 \\
\hline 15. Hummus & & $.272 \mathrm{a}$ & & .074 & 51. Automobile & & $.140 \mathrm{a}$ & & .020 \\
\hline 16. Arak§ & & & $.133 \mathrm{a}$ & .018 & Communication//Media & & & & \\
\hline 17. Shawarma & & & $.138 \mathrm{a}$ & .019 & 52. Watch television & $.102 \mathrm{~b}$ & $.263 \mathrm{a}$ & & .068 \\
\hline 18. Manakish & & $.196 \mathrm{a}$ & & .038 & 53. Use cell/mobile-phone & $.230 \mathrm{a}$ & & & .053 \\
\hline 19. Labneh & & $.184 \mathrm{a}$ & & .034 & 54. Use personal-computer & $.315 \mathrm{a}$ & & & .099 \\
\hline 20. Turkish-coffee & & & $.143 \mathrm{a}$ & .020 & 55. Use/surf Internet & $.342 \mathrm{a}$ & & & .117 \\
\hline 21. Laban-ayran & & $.106 \mathrm{~b}$ & & .011 & 56. Send emails§ & $.290 \mathrm{a}$ & & $.152 \mathrm{a}$ & .170 \\
\hline 22. Kebbe & & $.283 \mathrm{a}$ & $-.123 b$ & .059 & 57. Send text-messages & $.313 \mathrm{a}$ & & & .098 \\
\hline 23. Oriental-sweets & & $.254 \mathrm{a}$ & & .064 & 58. Use automated-banking-machines $\S$ & $.210 \mathrm{a}$ & & $.192 \mathrm{a}$ & .138 \\
\hline 24. Tabbouleh/fattoush & & $.221 \mathrm{a}$ & & .049 & 59. Purchase movie/music DVDs & $.268 \mathrm{a}$ & & & .072 \\
\hline 25. Lebanese-grills & & & $.180 \mathrm{a}$ & .032 & Luxuries & & & & \\
\hline 26. Traditional Lebanese-restaurants & & & $.301 \mathrm{a}$ & .091 & 60. Boxed-chocolates§ & & $.247 \mathrm{a}$ & & .061 \\
\hline Hygiene-Products & & & & & 61. Jewelry§ & & $-.122 b$ & $.301 \mathrm{a}$ & .067 \\
\hline 27. Hair-shampoo & & & & $\varnothing$ & 62. Expensive cosmetics & $.276 \mathrm{a}$ & & & .076 \\
\hline 28. Deodorants & $.166 \mathrm{a}$ & & & .028 & 63. Antique-furniture $\$$ & & & & $\emptyset$ \\
\hline 29. Toothpaste & & $.144 \mathrm{a}$ & & .021 & 64. Fur/Leather coats & & & $.146 \mathrm{a}$ & .021 \\
\hline 30. Hand/body-soap & & & $.149 \mathrm{a}$ & .022 & 65. Fragrances & & & $.209 \mathrm{a}$ & .044 \\
\hline Apparel/Fashion & & & & & 66. Expensive wine/champagne§ & $.241 \mathrm{a}$ & & & .058 \\
\hline 31. Blue-jeans & & & $.136 \mathrm{a}$ & .019 & \multicolumn{5}{|c|}{ *Significant standardized coefficients shown. $\mathrm{R}^{2}=$ squared multiple correlations (\% variance explained by } \\
\hline 32. Athletic-shoes & & & $.103 b$ & .011 & \multicolumn{5}{|l|}{ AGCC, LEID, A*L). } \\
\hline 33. Business-attire & $.197 \mathrm{a}$ & & & .039 & \multirow{3}{*}{\multicolumn{5}{|c|}{$\begin{array}{l}\text { §Significant consumption difference ( } \mathrm{p} \leq .05 \text { ) between Muslims/Christians (t-tests) } \\
\mathrm{a}: \mathrm{p}<.01, \mathrm{~b}: \mathrm{p}<.05\end{array}$}} \\
\hline 34. American-fashions & $.544 \mathrm{a}$ & & & .296 & & & & & \\
\hline 35. European-fashions & & $-.525 \mathrm{a}$ & $.564 \mathrm{a}$ & .285 & & & & & \\
\hline 36. Traditional-Lebanese-fashions & $-.197 \mathrm{a}$ & $.248 \mathrm{a}$ & & .121 & & & & & \\
\hline
\end{tabular}


Table 3: Acculturation Patterns Manifested in Consumption Behaviors

\begin{tabular}{|c|c|c|}
\hline Assimilation (AGCC+, LEID-/n.s.) & \multicolumn{2}{|c|}{ Integration/Creolization (AGCC+, LEID+) } \\
\hline Christians (18) & Muslims (10) & Christians (19) \\
\hline $\begin{array}{c}\text { (14) Sushi, burgers, baguette, alcoholic-beverages, Asian-restaurants, } \\
\text { European-restaurants, fast-food-restaurants, American-fashion, European- } \\
\text { fashion, business-attire, personal-music-player, DVD-player, surf-Internet, } \\
\text { expensive-wine/champagne }\end{array}$ & \multicolumn{2}{|c|}{ (1) Lebanese-restaurants } \\
\hline 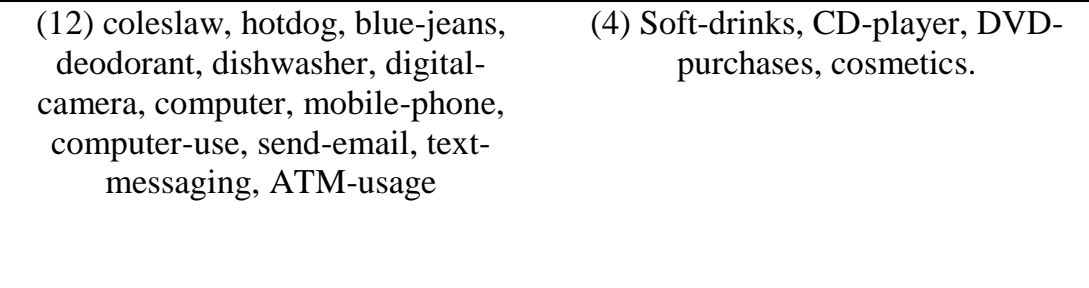 & $\begin{array}{l}\text { (9) cereal, Lebanese-grills, CD- } \\
\text { player, DVD-purchases, cosmetics, } \\
\text { fragrances, boxed-chocolates, } \\
\text { fur/leather-coats jewelry }\end{array}$ & $\begin{array}{l}\text { (18) Hummus, blue-jeans, deodorant, } \\
\text { toothpaste, soap, refrigerator, } \\
\text { microwave, dishwasher, vacuum, } \\
\text { videogame-console, digital-camera, } \\
\text { computer, mobile-phone, text- } \\
\text { messaging, ATM-usage, watch-TV, } \\
\text { computer-use, send-email }\end{array}$ \\
\hline $\begin{array}{l}\text { Deculturation (LEID-, AGCCn.s.) } \\
\text { or Marginalization (AGCCn.s., LEIDn.s.) }\end{array}$ & \multicolumn{2}{|c|}{$\begin{array}{c}\text { Separation (AGCCn.s., LEID+) } \\
\text { or Segregation (AGCC-, LEID+) }\end{array}$} \\
\hline Christians (18) & Muslims (14) & Christians(11) \\
\hline $\begin{array}{c}\text { (8) pizza, croissants, arak, shawarma, hair-shampoo, athletic-shoes, bicycle, } \\
\text { antique-furniture }\end{array}$ & \multicolumn{2}{|c|}{$\begin{array}{c}\text { (6) TV-set, washing-machine, manakish, oriental-sweets, taboulleh/fattoush, } \\
\text { Lebanese-fashion* }\end{array}$} \\
\hline $\begin{array}{cc}\text { (8) Turkish-coffee, soft-drinks, } & \text { (10) Labneh, cereal, tea, laban- } \\
\text { toothpaste, soap, videogame-console, } \\
\text { refrigerator, microwave, vacuum }\end{array} \quad \begin{array}{c}\text { ayran, coleslaw, hotdog, VCR, auto, } \\
\text { jewelry, fur/leather-coats }\end{array}$ & $\begin{array}{l}\text { (8) auto, VCR, watch-TV, labneh, } \\
\text { laban-ayran, kebbe, hummus*, tea* }\end{array}$ & $\begin{array}{l}\text { (5) Turkish-coffee, Lebanese-grills, } \\
\text { boxed-chocolates, fragrances, kebbe* }\end{array}$ \\
\hline
\end{tabular}


Appendix A: EFA Construct Measures

\begin{tabular}{|c|c|c|c|c|}
\hline Construct, Overall Reliability, Reliabilities for English-, French-, and Arabic-Language Versions (ao, ae, af, aa) & & Muslims (n=200) & Christians (n=192) & Contrast* \\
\hline & Loading & $\begin{array}{c}\text { Mean } \dagger(\text { SE) } \\
\text { Reliability }(\alpha)\end{array}$ & $\begin{array}{c}\text { Mean } \uparrow(\mathrm{SE}) \\
\text { Reliability }(\alpha)\end{array}$ & $\begin{array}{c}\text { Model F } \\
\text { Religion F }\end{array}$ \\
\hline English-Language Use (ELU), $(\alpha \mathrm{o}=.889, \alpha \mathrm{e}=.801, \alpha \mathrm{f}=.866, \alpha \mathrm{a}=.877)$ & & $3.92(.11)$ & $4.53(.11)$ & $25.17(\mathbf{p}<.001)$ \\
\hline -Many of my favorite television shows are in English. & .853 & .904 & .859 & $16.51(\mathrm{p}<.001)$ \\
\hline -The songs I listen to are almost all in English. & .826 & & & \\
\hline -I mostly carry on conversations in English every day. & .800 & & & \\
\hline -I prefer to watch English-language television over any other language I may speak. & .778 & & & \\
\hline -I speak English regularly. & .761 & & & \\
\hline -I feel very comfortable speaking in English. & 647 & & & \\
\hline Cosmopolitanism (COS), $(\alpha \mathrm{o}=.714, \alpha \mathrm{e}=.733, \alpha \mathrm{f}=.726, \alpha \mathrm{a}=.691)$ & & $5.49(.08)$ & $5.45(.08)$ & $2.62(\mathrm{p}=.074)$ \\
\hline -I like to observe people from other cultures, to see what I can learn from them. & 761 & 726 & .706 & $.147(\mathrm{p}=.701)$ \\
\hline -I enjoy exchanging ideas with people from other cultures or countries. & 745 & & & \\
\hline -I am interested in learning more about people who live in other countries. & 677 & & & \\
\hline -I enjoy being with people from other countries to learn about their views and approaches. & 640 & & & \\
\hline Global Mass Media-USA (GMMUSA), $(\alpha \mathrm{o}=.827, \alpha \mathrm{e}=.778, \alpha \mathrm{f}=.871, \alpha \mathrm{a}=.815)$ & & $4.85(.10)$ & $5.24(.10)$ & $12.94(\mathrm{p}<.001)$ \\
\hline -I enjoy watching American films/movies. & .798 & .858 & .775 & $7.30(p=.007)$ \\
\hline -I often watch American television programs. & 738 & & & \\
\hline -Some of my favorite actors/actresses are from the United States. & 712 & & & \\
\hline Global Mass Media-Europe (GMMEURO), $(\alpha \mathrm{o}=.882, \alpha \mathrm{e}=.868, \alpha \mathrm{f}=.915, \alpha \mathrm{a}=.881)$ & & $3.49(.10)$ & $4.06(.11)$ & $9.11(p<.001)$ \\
\hline -I like to read magazines that contain information about popular European celebrities. & .863 & .905 & .849 & $14.74(p<.001)$ \\
\hline -I enjoy watching European films. & .855 & & & \\
\hline -Some of my favorite actors/actresses are from Europe. & .780 & & & \\
\hline -I enjoy reading magazines from European countries. & .729 & & & \\
\hline -I enjoy listening to music that is popular in European countries (e.g., House, Trance, Euro Dance, etc.). & .724 & & & \\
\hline Openness to Global Consumer Culture (OPGCC), $(\alpha \mathrm{o}=.619, \alpha \mathrm{e}=.574, \alpha \mathrm{f}=.449, \alpha \mathrm{a}=.669)$ & & $3.34(.11)$ & $3.85(.11)$ & $5.43(p=.005)$ \\
\hline -I like the way people live in Europe. & .842 & .623 & 620 & $10.86(\mathrm{p}=.001)$ \\
\hline -Globalization is generally a good thing. & .766 & & & \\
\hline Exposure to Marketing Activities of MNC's (EXM), $(\alpha 0=.589, \alpha \mathrm{e}=.700, \alpha \mathrm{f}=.803, \alpha \mathrm{a}=.383)$ & & $4.32(.08)$ & $4.51(.08)$ & $2.75(\mathrm{p}=.065)$ \\
\hline -When I read a newspaper, I come across many advertisements for foreign or global products. & .711 & .618 & .534 & $2.72(\mathrm{p}=.100)$ \\
\hline -When I am watching TV, I often see advertising for products that are from outside of my country. & 698 & & & \\
\hline $\begin{array}{l}\text {-When I am watching TV, it seems that the number of advertisements for foreign brands is quite high, when compared to } \\
\text { the number of advertisements for local brands. }\end{array}$ & 606 & & & \\
\hline Travelling Frequencies/Attitudes (TRAV), $(\alpha \mathrm{o}=.684, \alpha \mathrm{e}=.530, \alpha \mathrm{f}=.674, \alpha \mathrm{a}=.700)$ & & $4.52(.08)$ & $4.80(.09)$ & $17.46(\mathrm{p}<.001)$ \\
\hline -I prefer spending my vacations outside of the country that I live in. & .751 & .732 & .551 & $4.68(p=.031)$ \\
\hline -While vacationing, I would prefer to stay in my home country, rather than visit another country (reversed) & .666 & & & \\
\hline - Visiting foreign countries is one of my favorite things. & .633 & & & \\
\hline -I have travelled extensively outside my home country. & 631 & & & \\
\hline Self-Identification with Global Consumer Culture (GCIDT), $(\alpha \mathrm{o}=.684, \alpha \mathrm{e}=.645, \alpha \mathrm{f}=.762, \alpha \mathrm{a}=.664)$ & & $4.06(.09)$ & $4.23(.09)$ & $6.16(p=.002)$ \\
\hline -I pay attention to the fashions worn by people in my age-group that live in other countries. & 742 & .671 & 680 & $1.70(\mathrm{p}=.197)$ \\
\hline -Advertising by foreign or global brands has a strong influence on my clothing choices. & 739 & & & \\
\hline -The way that I dress is influenced by the advertising activities of foreign or global companies. & .600 & & & \\
\hline AGCC Composite & & $4.25(.06)$ & $4.58(.06)$ & $\begin{array}{l}21.69(p<.001) \\
17.01(p<.001)\end{array}$ \\
\hline 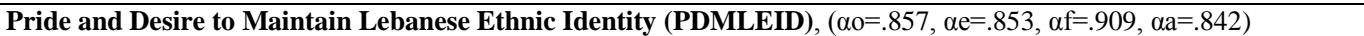 & & $4.87(.08)$ & $4.93(.08)$ & $.349(\mathrm{p}=.706)$ \\
\hline -If I was to live elsewhere, I would still want to retain the Lebanese culture. & .800 & .867 & .827 & $.284(\mathrm{p}=.594)$ \\
\hline -I feel very much a part of the Lebanese culture. & 795 & & & \\
\hline -It is very important for me to remain close to the Lebanese culture. & .785 & & & \\
\hline
\end{tabular}




\begin{tabular}{|c|c|c|c|c|}
\hline $\begin{array}{l}\text {-I feel most comfortable in the Lebanese culture. } \\
\text {-I consider the Lebanese culture rich and precious. } \\
\text {-The Lebanese culture has the most positive impact on my life. }\end{array}$ & $\begin{array}{l}.714 \\
.703 \\
.687\end{array}$ & & & \\
\hline Arabic-Language Use (ALU), $(\alpha \mathrm{o}=.795, \alpha \mathrm{e}=.830, \alpha \mathrm{f}=.864, \alpha \mathrm{a}=.744)$ & & $6.48(.07)$ & $6.35(.07)$ & $4.79(\mathrm{p}=.009)$ \\
\hline -The songs I listen to are almost all in Arabic. & .833 & .790 & .784 & $1.93(\mathrm{p}=.165)$ \\
\hline -Many of my favorite television shows are in Arabic. & .828 & & & \\
\hline -I mostly carry on conversations in Arabic every day. & .789 & & & \\
\hline -I speak Arabic regularly. & .652 & & & \\
\hline Arabic-Media Usage (AMU), $(\alpha \mathrm{o}=.684, \alpha \mathrm{e}=.724, \alpha \mathrm{f}=.820, \alpha \mathrm{a}=.568)$ & & $3.45(.10)$ & $3.33(.10)$ & $16.69(\mathrm{p}<.001)$ \\
\hline -The movies/videos that I watch are always in Arabic. & .896 & .708 & .637 & $.786(\mathrm{p}=.376)$ \\
\hline -The newspapers that I read are always in Arabic. & .864 & & & \\
\hline -The television shows that I watch are always in Arabic. & .839 & & & \\
\hline Ethnic Customs (ECUS) $(\alpha \mathrm{o}=.597, \alpha \mathrm{e}=.643, \alpha \mathrm{f}=.674, \alpha \mathrm{a}=.544)$ & & $4.79(.09)$ & $4.87(.09)$ & $4.53(p=.011)$ \\
\hline -I always celebrate Lebanese culture holidays. & .790 & .614 & .584 & $.409(\mathrm{p}=.523)$ \\
\hline -I like to celebrate birthdays and weddings in the Lebanese cultural tradition. & .740 & & & \\
\hline -I like to cook Lebanese culture dishes/meals. & .632 & & & \\
\hline EID Composite & & $4.90(.05)$ & $4.87(.06)$ & $\begin{array}{c}11.84(\mathrm{p}<. .001) \\
.133(\mathrm{p}=.716)\end{array}$ \\
\hline Materialism (MAT), $\left(\alpha 0=.716, \alpha \mathrm{e}^{\prime} .706, \alpha \mathrm{f}=.816, \alpha \mathrm{a}=.679\right)$ & & $4.48(.08)$ & $4.60(.09)$ & $3.08(p=.047)$ \\
\hline-5 items (adopted from Richins, 2004) & & .704 & 719 & $1.00(\mathrm{p}=.317)$ \\
\hline Consumer Ethnocentrism $($ CET $),(\alpha 0=.774, \alpha \mathrm{e}=.818, \alpha \mathrm{f}=.828, \alpha \mathrm{a}=.737)$ & & $4.34(.09)$ & $4.57(.10)$ & $7.20(\mathbf{p}<.001)$ \\
\hline-4 items (adopted from Klein, 2002) & & .776 & .759 & $2.80(\mathrm{p}=.095)$ \\
\hline Religiosity Factor 1 (REL1), $(\alpha \mathrm{o}=.916, \alpha \mathrm{e}=.941, \alpha \mathrm{f}=.947, \alpha \mathrm{a}=.882)$ & & $4.98(.09)$ & $4.80(.09)$ & $5.87(\mathrm{p}=.003)$ \\
\hline -I consider myself active in my faith (I spend some time in church or mosque). & .845 & .909 & .909 & $1.99(\mathrm{p}=.159)$ \\
\hline -My faith is an important part of who I am as a person. & .796 & & & \\
\hline -I look to my faith as providing meaning and purpose in my life. & .789 & & & \\
\hline -My religious beliefs lie between my whole purpose in life. & .749 & & & \\
\hline -Religion is especially important to me because it answers many questions about the meaning of life. & .719 & & & \\
\hline -My religious faith is extremely important to me. & .700 & & & \\
\hline -It is important for me to spend periods of time in private religious thought and prayer. & .696 & & & \\
\hline -My religious beliefs influence many of my decisions and dealings in life. & .692 & & & \\
\hline -I pray every time I'm supposed to. & .648 & & & \\
\hline -I look to my faith as a source of comfort. & .645 & & & \\
\hline Religiosity Factor $2($ REL2), $(\alpha \mathrm{o}=.764, \alpha \mathrm{e}=.825, \alpha \mathrm{f}=.820, \alpha \mathrm{a}=.720)$ & & $3.60(.11)$ & $3.95(.11)$ & $3.10(p=.046)$ \\
\hline -I keep well informed about my local religious group and have influence in its decisions. & .803 & .733 & .783 & $5.36(\mathrm{p}=.021)$ \\
\hline -I make financial contributions to my religious organization (Zakat). & .791 & & & \\
\hline -I enjoy participating in the activities of my religious organization. & .790 & & & \\
\hline French-Language Usage $($ FLU $),(\alpha 0=.909, \alpha \mathrm{e}=.919, \alpha \mathrm{f}=.884, \alpha \mathrm{a}=.898)$ & & $3.26(.11)$ & $3.88(.12)$ & $8.67(p<.001)$ \\
\hline -Many of my favorite television shows are in French. & .862 & .920 & .887 & $15.01(\mathrm{p}<.001)$ \\
\hline -I mostly carry on conversations in French every day. & .858 & & & \\
\hline -The songs I listen to are almost all in French. & .844 & & & \\
\hline -I prefer to watch French-language television over any other language I may speak. & .837 & & & \\
\hline -I feel very comfortable speaking in French. & .809 & & & \\
\hline -I always speak French with family members. & .758 & & & \\
\hline -I speak French regularly & .657 & & & \\
\hline Mean Rating Schwartz Values (MRAT) & & $5.18(.06)$ & $5.16(.06)$ & $\begin{array}{l}.011(\mathrm{p}=.989) \\
.017(\mathrm{p}=.897)\end{array}$ \\
\hline Conformity, $(\alpha \mathrm{o}=.653, \alpha \mathrm{e}=.661, \alpha \mathrm{f}=.680, \alpha \mathrm{a}=.636)$ & & $5.57(.06)$ & $5.37(.06)$ & $156.86(\mathbf{p}<.001)$ \\
\hline $\mathrm{HCH}_{\mathrm{H}}$ & & .616 & .684 & $6.22(p=.013)$ \\
\hline Tradition, $(\alpha \mathrm{o}=.580, \alpha \mathrm{e}=.531, \alpha \mathrm{f}=.588, \alpha \mathrm{a}=.597)$ & & $4.80(.06)$ & $4.70(.06)$ & $180.84(\mathbf{p}<.001)$ \\
\hline
\end{tabular}




\begin{tabular}{|c|c|c|c|}
\hline-5 items & .552 & .622 & $1.87(\mathrm{p}=.172)$ \\
\hline Benevolence, $(\alpha \mathrm{o}=.736, \alpha \mathrm{e}=.669, \alpha \mathrm{f}=.807, \alpha \mathrm{a}=.752)$ & $5.55(.05)$ & $5.39(.05)$ & $257.65(p<.001)$ \\
\hline-5 items & .731 & .753 & $5.89(\mathrm{p}=.016)$ \\
\hline Universalism, $(\alpha \mathrm{o}=.756, \alpha \mathrm{e}=.724, \alpha \mathrm{f}=.668, \alpha \mathrm{a}=.786)$ & $5.29(.04)$ & $5.32(.04)$ & $365.66(p<.001)$ \\
\hline-8 items & .750 & .767 & $.137(\mathrm{p}=.711)$ \\
\hline Self-Direction, $(\alpha \mathrm{o}=.632, \alpha \mathrm{e}=.631, \alpha \mathrm{f}=.426, \alpha \mathrm{a}=.666)$ & $5.41(.04)$ & $5.47(.05)$ & $260.46(p<.001)$ \\
\hline-5 items & .530 & .718 & $.851(\mathrm{p}=.357)$ \\
\hline Stimulation, $(\alpha \mathrm{o}=.545, \alpha \mathrm{e}=.728, \alpha \mathrm{f}=.511, \alpha \mathrm{a}=.488)$ & $4.51(.08)$ & $4.86(0.8)$ & $91.06(p<.001)$ \\
\hline-3 items & .448 & .633 & $9.72(\mathrm{p}=.002)$ \\
\hline Hedonism, $(\alpha \mathrm{o}=.606, \alpha \mathrm{e}=.520, \alpha \mathrm{f}=.612, \alpha \mathrm{a}=.575)$ & $4.43(.11)$ & $4.84(.11)$ & $39.14(\mathbf{p}<.001)$ \\
\hline-2 items & .577 & .632 & $6.70(\mathrm{p}=.009)$ \\
\hline Achievement, $(\alpha \mathrm{o}=.625, \alpha \mathrm{e}=.719, \alpha \mathrm{f}=.714, \alpha \mathrm{a}=.567)$ & $5.42(.05)$ & $5.42(.05)$ & $230.49(\mathrm{p}<.001)$ \\
\hline-4 items & 627 & .628 & $.001(\mathrm{p}=.977)$ \\
\hline Power, $(\alpha \mathrm{o}=.666, \alpha \mathrm{e}=.745, \alpha \mathrm{f}=.474, \alpha \mathrm{a}=.652)$ & $3.43(.11)$ & $3.85(.11)$ & $31.01(p<.001)$ \\
\hline-3 items & .654 & .648 & $7.08(\mathrm{p}=.008)$ \\
\hline Security, $(\alpha \mathrm{o}=.671, \alpha \mathrm{e}=.492, \alpha \mathrm{f}=.746, \alpha \mathrm{a}=.727)$ & $5.93(.05)$ & $5.76(.05)$ & $162.54(p<.001)$ \\
\hline-5 items & .636 & .679 & $6.01(p=.015)$ \\
\hline
\end{tabular}

*Overall sample loadings $(\mathrm{n}=399)$. English (125), French (58), Arabic (216) surveys. EFA retained items. $\uparrow$ Adjusted means, covariates=income (3.78) and — where applicable-

MRAT (5.17). SE=standard-error. *Model-F (Regression), Religion-F (main effect).

\section{Appendix B: Behavioral Measures}

On a scale of 1 to 7 , how often do you...*

[1=never, $7=$ daily $] \ldots$ * consume?

pizza, hummus, sushi, hamburgers, croissants, baguette, arak, other alcoholic-beverages (wine, beer, vodka, etc.), shawarma, manakish, labneh, cornflakes/cereal, tea, Turkish-

coffee, laban ayran, soft-drinks, kebbe, oriental-sweets (baklava, knafe, etc.), tabbouleh/fattoush, coleslaw, Lebanese-grills (kabab, shish-tawuk, etc.), hotdog

[1=never, $7=$ daily $] \ldots *$ use/wear?

Hair-shampoo, blue (denim) jeans, deodorant, athletic/running-shoes, business-suits/attire, toothpaste, hand/body-soap

$[1(7)=$ not at all (very) essential] ... for you, how essential (important) are?

Personal-music-player (e.g., Walkman, iPod), washing-machine, dishwasher-machine, refrigerator, vacuum-cleaner, compact-disc-player, videogame-console, DVD (digitalvideo-disc) player, VCR (video-cassette-recorder), microwave-oven, television-set, digital-camera, personal (and/or laptop) computer, bicycle, automobile

[1=never, $7=$ daily $] \ldots *$ *

watch television, use a cell/mobile-phone, use a personal/laptop-computer, use/surf the Internet (world-wide-web), send email (electronic-mail), send text-messages, use an automatic-banking-machine (ATM)

$[1=$ never, $7=$ several times per week $] \ldots *$

visit traditional-Lebanese restaurants (...restaurants that offer Asian [European, American-style fast-] food/meals, e.g.,...), wear traditional-Lebanese (American, Asian, European) fashions

[1=never, $7=$ at least once per month $]. . *$ purchase...?

boxed-chocolates, cosmetics, fragrances (e.g., perfumes/colognes), music or movie DVDs

$[1=$ never, $7=$ several times per year $] \ldots{ }^{*}$ purchase...?

jewelry, antique-furniture, fur/leather coats, expensive wine/champagne 
Appendix C: Correlations ${ }^{\text {ab }}$

\begin{tabular}{|c|c|c|c|c|c|c|c|c|c|c|c|c|c|c|c|c|}
\hline & $\stackrel{2}{\Omega}$ & 島 & 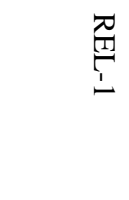 & 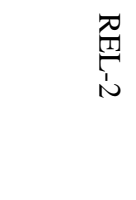 & $\underset{-3}{3}$ & 盘 & 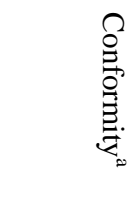 & 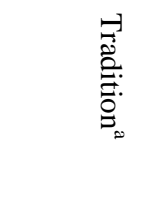 & 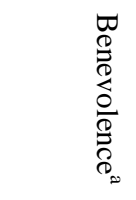 &  & 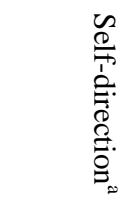 & 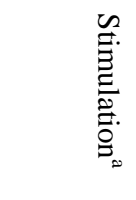 & 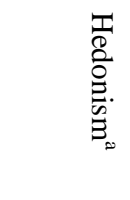 & 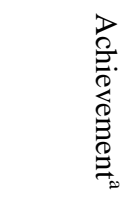 &  &  \\
\hline AGCC & $\mathbf{1}$ & & & & & & & & & & & & & & & \\
\hline LEID & $-30 * /-.03$ & 1 & & & & & & & & & & & & & & \\
\hline REL-1 & $-.06 / .06$ & $33 \% / 48 *$ & 1 & & & & & & & & & & & & & \\
\hline REL-2 & $-.10 / 27 *$ & $.28 * / 34 *$ & $59 * 63^{*}$ & 1 & & & & & & & & & & & & \\
\hline MAT & $.16 * / 45^{*}$ & $.06 / 32 *$ & $.21 * .16^{*}$ & $.15 * / 26 *$ & 1 & & & & & & & & & & & \\
\hline CET & $-.23 *-.07$ & $\mathbf{A B} \% \mathbf{A} \mathbf{8}^{*}$ & $.19 * / 40^{*}$ & $.15 * / 21 *$ & $.02 / .19^{*}$ & 1 & & & & & & & & & & \\
\hline Conformity $^{\mathrm{a}}$ & $-.21 * / . .19 *$ & $.13 / 20^{*}$ & $.27 * / 31^{*}$ & $.16 * / .07$ & $.06 /-.12$ & $.19 * / .07$ & 1 & & & & & & & & & \\
\hline Tradition $^{\mathrm{a}}$ & $-37 * /-20 *$ & $29 * / 09$ & $.35 * / 30^{*}$ & $.37 * / 22 *$ & $-.06 /-30^{*}$ & $.17 * .22^{*}$ & $.33 * / 35^{*}$ & 1 & & & & & & & & \\
\hline Benevolence $^{\mathrm{a}}$ & $-.05 /-.05$ & .06 .10 & $.17 * .07$ & $.18 * / .03$ & $-.15 *-.17 *$ & $-.04 /-.15^{*}$ & .10 .02 & .10 .11 & 1 & & & & & & & \\
\hline Universalism $^{\mathrm{a}}$ & $.04-.06$ & $.06 / .02$ & $-.12 /-.05$ & $-.10 /-.19 *$ & $-.15 * / .12$ & $.18 * / 02$ & $-.04 /-.10$ & $-20 *-20 *$ & $-.18 \% / 12$ & 1 & & & & & & \\
\hline Self-direction ${ }^{a}$ & $.10 .20^{*}$ & $-.12 /-21^{*}$ & $-.17 *-.18^{*}$ & $-25 *-.08$ & $-24 * / .01$ & $-.16 *-.08$ & $-21 * /-32 *$ & $-28 *-37 *$ & $-.04 /-.13$ & $.09 / .02$ & 1 & & & & & \\
\hline Stimulation $^{\mathrm{a}}$ & $20 \% 1.19 *$ & $-22 * /-28 *$ & $-27 *-29 *$ & $-.16 *-.20 *$ & $-.01 / .01$ & $-27 *-.10$ & $-30 *-37 *$ & $-.10 /-.18^{*}$ & $-.18 *-.27 *$ & $-21 * /-.11$ & $-.00 \% .08$ & 1 & & & & \\
\hline Hedonism $^{\mathrm{a}}$ & $34 * / 29 *$ & $-31 \% / . .13$ & $-.12 /-.16^{*}$ & $-.04 /-.02$ & $.10 / 27^{*}$ & $-.21 *-.09$ & $-.40 *-.42 *$ & $-31 *-51 *$ & $-.13 /-.29 *$ & $-21 *-.13$ & $-.03 / 28^{*}$ & $.25 * / 27 *$ & 1 & & & \\
\hline Achievement $\mathrm{t}^{\mathrm{a}}$ & $-.08 / .10$ & $-.01 /-.07$ & $-.04 /-.09$ & $-.09 / 01$ & $-.09 /-.01$ & $-.02 /-25^{*}$ & $-.12 /-.16^{*}$ & $-.15 *-.19 *$ & $.07 /-.05$ & $-20 * /-.17 *$ & $-.02 / 10$ & $-.06 / .12$ & $-.13 /-.05$ & 1 & & \\
\hline Power $^{\mathrm{a}}$ & $.15 * 16^{*}$ & $-.02 /-.03$ & $-.09 /-03$ & $-.01 / 23^{*}$ & $.29 * / 31 *$ & $.02 / .06$ & $-29 * / .18 *$ & $-25 * .02$ & $-49 *-39 *$ & $-20 *--45 *$ & $-.13 /-.18^{*}$ & $.05 / .04$ & $20 \% .14$ & $-.03 /-.04$ & 1 & \\
\hline Security $^{\mathrm{a}}$ & $-.09 /-.19 *$ & $-.04 / .17^{*}$ & $-.05 / .01$ & $-.12-.15^{*}$ & $.08 / 10$ & $-.06 * .09$ & $.15 \% / 14$ & $-.19 *-.23 *$ & $-.06 /-.05$ & $.09 / .03$ & $-.06 / .01$ & $-26 *-.28 *$ & $-22 * /-.02$ & $-.14 *-.16 *$ & $-.18 *-.26 *$ & 1 \\
\hline
\end{tabular}

${ }^{\mathrm{a}}$ Partial correlation coefficients $(\rho){ }^{\mathrm{b}}$ Muslims/Christians. ${ }^{*} \mathrm{p}<.05$ (two-tailed). 